\title{
Consider surgery for elderly patients
}

\author{
Mark R. Katlic MD MMM
}

Previously published at www.cmaj.ca

$\infty \infty \quad$ See related research article by Pagé and colleagues, page 1415

A mong the comorbidities associated with age, cardiovascular disease is the most deadly, ranking first among causes of death among the elderly in both developed and developing countries around the world. ${ }^{1,2}$ The timely article by Pagé and colleagues ${ }^{3}$ addresses trends in the invasive treatment of coronary artery disease after acute myocardial infarction in octogenarians. The authors report that, despite an increasing prevalence of comorbidities (and likely underreporting of same owing to the nature of the administrative database mined), an impressive growth in coronary revascularization procedures occurred between 1996 and 2007 in Quebec. Use of percutaneous coronary intervention in patients who had experienced a first acute myocardial infarction increased from $2.2 \%$ to $24.9 \%$, and use of coronary artery bypass graft in such patients increased from $0.8 \%$ to $3.1 \%$. Mortality also improved over this period.

Given that no changes in mortality occurred in the group having no revascularization, percutaneous coronary intervention and coronary artery bypass graft appear to have helped those patients who underwent intervention. However, the study was retrospective and, in an obvious way, selective: patients undergoing revascularization must survive myocardial infarction long enough to have the procedure. In addition, as the authors themselves point out, the study did not control for use of in-hospital medication, including thrombolytics, for cardiac ejection fraction or for biomarkers of myocardial infarction. Data on the functional state of the patients and their quality of life could not be studied. Nevertheless, the data dramatically show increasing use of aggressive, invasive procedures in patients once believed to be too old for such procedures.

What do we know about surgery in the elderly that will help us improve the results of such procedures? Six general

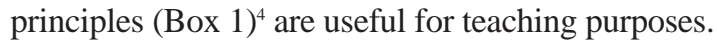

The clinical presentation of surgical problems in the elderly may be subtle or somewhat different from that in the general population; this may lead to delay in diagnosis. For example, unstable angina is as likely to present as dyspnea, nausea or diaphoresis as it is with classic chest pain. ${ }^{5}$ Naughton and colleagues recently reported that, in a series of patients who underwent coronary artery bypass graft, only $62 \%$ of the group aged 75 and older were referred for elective surgery versus $77 \%$ in the younger cohort. ${ }^{6}$ The elderly handle stress satisfactorily but handle severe stress poorly

\section{Key points}

- The population is aging and conditions that require surgery increase with age.

- Elderly patients can tolerate stress, but owing to lack of reserve, they may not withstand severe stress or complications.

- No particular age, of itself, is a contraindication to surgery.

because of lack of organ-system reserve. When patients over 70 years of age undergo a third coronary reoperation, only those in the worst Canadian functional class have increased mortality, and this increase is not seen in young patients in a similar class. ${ }^{7}$ In a study by de Liguori Carino and colleagues ${ }^{8}$ of 181 liver resections for colon cancer metastases in patients aged 65-85 years, liver failure occurred only after resection of four or more segments, and all but one death occurred after a major resection.

Optimal preoperative preparation is essential because of the lack of reserve. Hypovolemia must be corrected, as should hypertension, bronchitis and severe anemia. When there is not time for such preparation, as in emergency surgery, perioperative risk rises sharply. ${ }^{6,9}$ Of course, the risk of emergency operation is higher in all age groups, but in the elderly, this difference may approach one order of magnitude. Scrupulous attention to detail yields great benefit, given that the elderly tolerate complications poorly. Perioperative blood loss, for example, is the bête noire of geriatric surgery, and ironically, is also the factor over which the surgeon has the most control. Zingone and colleagues concluded that "postoperative complications were stronger risk factors for hospital deaths than preoperative comorbidities and procedural variables.",

Finally, a patient's age should be treated as a scientific fact, not with prejudice. No particular chronologic age, of itself, is a contraindication to operation. Even an 80-year-old man has a life expectancy of eight years, so why not offer him resection of his lung cancer? No other treatment is likely to give him those eight years. Yet this is not always done: prejudice based on chronologic age, or "ageism," exists in society and in medicine. Cardiac surgery may not even be discussed as an option

Mark Katlic is the Director of Thoracic Surgery, Geisinger Health System, Wilkes-Barre, USA.

\section{CMAJ 2010. DOI:10.1503/cmaj.100780}


Box 1: Principles of geriatric surgery ${ }^{4}$ (reprinted with permission from Springer)

I. The clinical presentation of surgical problems in the elderly may be subtle or somewhat different from that in the general population. This may lead to delay in diagnosis.

II. The elderly handle stress satisfactorily, but handle severe stress poorly because of lack of organ-system reserve.

III. Optimal preoperative preparation is essential because of Principle II. When preparation is suboptimal, perioperative risk increases.

IV. The results of elective surgery in the elderly are reproduceably good; the results of emergency surgery are poor though still better than nonoperative treatment for most conditions. The risk of emergency surgery may be many times that of similar elective surgery because of Principles II and III.

V. Scrupulous attention to detail intraoperatively and perioperatively yields great benefit, as the elderly tolerate complications poorly (because of Principle II).

VI. A patient's age should be treated as a scientific fact, not with prejudice. No particular chronologic age, of itself, is a contraindication to operation (because of Principle IV).

for the octogenarian with mitral valve disease $;^{10}$ the elderly patient with cancer is more likely to experience suboptimal staging and less aggressive treatment. In a 2007 editorial, Siu ${ }^{11}$ concluded that "ageism is probably the greatest impediment to the enrollment of older patients in trials for cancer therapy."

The elderly patient, compared with one younger, will have reduced physiologic reserve and a greater likelihood of comorbidities, may have a longer length of stay in hospital and greater cost of care. But there is great physiologic variability in the older population, and published results of surgery in the elderly do not support discrimination based on age. Many groups have shown that excellent results are attainable with compulsive attention to detail. ${ }^{11,12}$ General medical state, stage of cancer, and functional status are far more important than age per se.

The study by Pagé and associates does not tell us whether interventions in the elderly are cost-effective or whether they should be done - just that they are being done, and in sharply rising numbers over just 10 years. We cannot ignore this trend.
Surgical problems abound in the elderly and the numbers of elderly are increasing worldwide. Surgeons must become students of the physiologic changes that occur with aging and, guided by a few general principles, apply this knowledge to daily clinical care. The results of surgery in the elderly do not support prejudice against advanced age. We owe it to our elders to become good geriatric surgeons, and in so doing, we will become better surgeons to patients of all ages.

This article was solicited and has not been peer reviewed.

Competing interests: None declared.

\section{REFERENCES}

1. Kinsella K, He W. An aging world: 2008: International population reports. P95/09-1, Washington (DC): US Census Bureau; 2009. Available: www.census .gov/prod/2009pubs/p95-09-1.pdf (accessed 2010 May 23).

2. World population aging 1950-2050. New York (NY): United Nations, Department of Economic and Social Affairs, Population Division; 2001. Available: www.un org/esa/population/publications/worldageing19502050/ (accessed 2010 May 23).

3. Pagé M. Doucet M, Eisenberg MJ, et al. Temporal trends in revascularization and outcomes after acute myocardial infarction among the very elderly. CMAJ 2010 Aug. 2 [Epub ahead of print].

4. Principles of geriatric surgery. In: Rosenthal RA, Zenilman ME, Katlic MR, editors. Principles and practice of geriatric surgery. New York (NY): Springer; 2001. p. $92-104$.

5. Canto JG, Fincher C, Kiefe CI, et al. Atypical presentations among Medicare beneficiaries with unstable angina pectoris. Am J Cardiol 2002;90:248-53.

6. Naughton C. Feneck Ro, Roxburgh J. Early and late predictors of mortality following on-pump coronary artery bypass graft surgery in the elderly as compared to a younger population. Eur J Cardiothorac Surg 2009;36:621-7.

7. Lytle BW, Navia JL, Taylor PC, et al. Third coronary artery bypass operations: risks and costs. Ann Thorac Surg 1997;64:1287-95.

8. de Liguori Carino N, van Leeuwen Bl, Ghaneh P, et al. Liver resection for colorectal liver metastases in older patients. Crit Rev Oncol Hematol 2008;67:273-8.

9. Zingone B, Gatti G, Rauber E, et al. Early and late outcomes of cardiac surgery in octogenarians. Ann Thorac Surg 2009;87:71-8.

10. Mirabel M, Iung B, Baron G, et al. What are the characteristics of patients with severe, symptomatic, mitral regurgitation who are denied surgery? Eur Heart $J$ 2007;28:1358-65.

11. Siu LL. Clinical trials in the elderly - a concept comes of age. N Engl J Med 2007; 356:1575-6.

12. Ghanta RK, Shekar PS, McGurk S, et al. Nonelective cardiac surgery in the elderly: is it justified? J Thorac Cardiovasc Surg 2010;140:103-9.

13. Rizzoli G, Bejko, Bottio T, et al. Valve surgery in octogenarians: does it prolong life? Eur J Cardiothorac Surg 2010;37:1047-55.

Correspondence to: Dr. Mark R. Katlic, Director of Thoracic Surgery, Geisinger Health System, 1000 East Mountain Blvd., Wilkes-Barre PA 18711, USA; mrkatlic@geisinger.edu

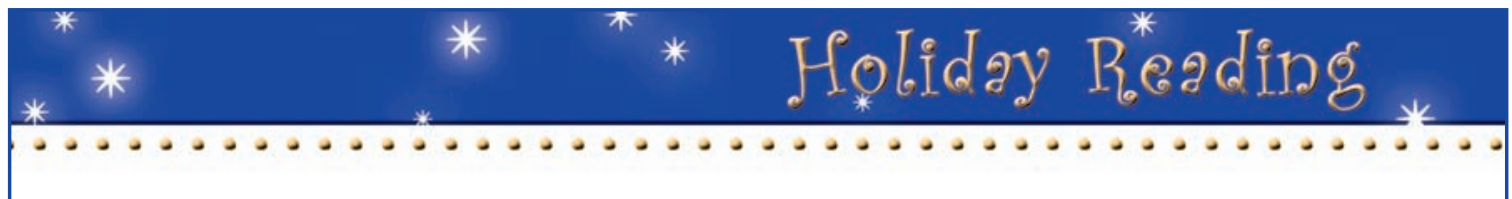

\section{Call for papers}

"Hilarity and good humour ... help enormously in both the study and the practice of medicine." — William Osler

Twisted research, humorous reflections, witty rants, culturally current missives — we'll consider it all for CMAJ's 2010 Holiday Reading. Articles should be no longer than 1200 words; photographs and illustrations are welcome. Please submit your amusing missive online at http://mc.manuscriptcentral .com/cmaj, and specify in your cover letter that it's for the Holiday Reading section.

Deadline: October 1, 2010. 